\title{
Fat soluble antioxidants in brood-rearing great tits Parus major: relations to health and appearance
}

\author{
Peeter Hõrak, Peter F. Surai, Indrek Ots and Anders P. Møller
}

\begin{abstract}
Hõrak, P., Surai, P.F., Ots, I. and Møller, A.P. 2004. Fat soluble antioxidants in brood-rearing great tits Parus major: relations to health and appearance. - J. Avian
\end{abstract} Biol. 35: 63-70.

\begin{abstract}
The concept of parasite-mediated sexual selection assumes that females may improve offspring fitness by selecting mates on the basis of sexual ornaments that honestly reveal the health state of a partner. Expression of such signals may be particularly sensitive to oxidative damage caused by excess production of oxidative metabolites and free radicals. To control and neutralise free radicals, animals rely heavily on dietary fat-soluble antioxidants such as vitamin E and A, and carotenoids. However, the organism's need for free radical scavenging may interfere with the opposite need to generate oxidative stress for fighting parasitic infections. We investigated plasma concentrations of carotenoids and vitamin $\mathrm{A}$ and $\mathrm{E}$ in brood-rearing great tits Parus major in relation to carotenoid-based plumage coloration, sex, habitat, leukocyte hemoconcentrations and infection status with Haemoproteus blood parasites. Rural great tits differed from urban ones and males from females with respect to the hue of the yellow ventral feathers. However, plasma antioxidant concentrations were not related to sex, habitat or plumage coloration. Plasma carotenoid concentration correlated positively with indices of immune system activation as measured by blood counts of lymphocytes and eosinophils. Birds with gametocytes of Haemoproteus in their blood had higher plasma concentrations of carotenoids and vitamin $\mathrm{E}$ than unparasitized individuals. These results are consistent with the idea that maintenance of high blood antioxidant levels might conflict with individual needs to rely on oxidative stress for fighting infections.
\end{abstract}

P. Horrak (correspondence) and I. Ots, Institute of Zoology and Hydrobiology, Tartu University, Vanemuise 46, 51014 Tartu,Estonia.E-mail:horak@ut.ee.P.F. Surai, Avian Science Research Centre, Scottish Agricultural College, Ayr KA6 5 HW, UK. A.P. Moller, Laboratorie de Parasitologie Evolutive, CRNS UMR 7103, Université Pierre et Marie Curie, Bât. A, 7ème étage, 7 quai St. Bernard, Case 237, F-75252 Paris Cedex 05, France.

According to the concept of parasite-mediated sexual selection (Hamilton and Zuk 1982, Andersson 1994) females would benefit by selecting mates on the basis of sexual ornaments and other signals that honestly reveal the health state of potential partners and their ability to provide parasite resistance genes for the offspring. Recently, von Schantz et al. (1999) hypothesised that the expression of such signals may be particularly sensitive to oxidative damage caused by an excess production of oxidative metabolites and free radicals. To control and neutralise free radicals, animals maintain a sophisticated system of chemical and biochemical defences based on antioxidants - chemical substances that deac- tivate (scavenge) free radicals by donating them missing electrons.

Dietary fat-soluble antioxidants such as vitamin E and $\mathrm{A}$, and carotenoids, constitute an important group of free radical scavengers. Vitamin $\mathrm{E}$ ( $\alpha$-tocopherol) is the most important lipid-soluble antioxidant in cellular membranes which protects the structure and functional integrity of subcellular organelles (e.g., Cherian and Sim 1997, Surai 1999). It protects cells involved in the immune response against oxidative damage and enhances the function and proliferation of these cells (e.g., Puthpongsiriporn et al. 2001). On the other hand, high levels of vitamin E may appear detrimental in situations

C JOURNAL OF AVIAN BIOLOGY 
where individuals rely on oxidative stress for fighting parasitic infections (reviewed by Allen et al. 1998). This is possible because not only host cells but also those of parasites are susceptible to free-radical damage generated in environments rich in pro-oxidants. Vitamin A (retinol) plays a vital role in the functioning of the retina, growth and maturation of epithelial cells, growth of bone, reproduction and embryonic development (e.g., Ross 1998). Because vitamin A participates in maintaining the integrity of skin and mucous membranes of the eyes and respiratory, urinary, and intestinal tracts, it plays an important role in protection against microbial infection (Ross 1998). Furthermore, antioxidant properties of vitamin A should also be taken into consideration (Olson 1993, Livrea et al. 1996).

Carotenoids are biochemically active pigments of a mainly botanical origin. They scavenge free radicals and decrease immunosuppressive peroxides, enhance the production of lymphocytes, the phagocytic ability of neutrophils and macrophages and tumor immunity (reviewed by Lozano 1994, Møller et al. 2000, Surai et al. 2001a). Carotenoids are usually considered as precursors of vitamin A, however, from more than 600 carotenoids described so far only 50 can be converted into vitamin A and only about 10 can have a substantial effect on vitamin A status (reviewed by Surai et al. 2001a, b). More importantly, it is well recognised now that all antioxidants are working together to provide effective antioxidant protection (Surai 2002). Different types of antioxidants can act in a complementary or synergistic way to each other, so that the reaction of one antioxidant can spare or even regenerate others (reviewed by von Schantz et al. 1999). Carotenoidbased pigments are disproportionally common components of animal signals used in sexual display, parent-offspring communication and in warning colours (reviewed by Møller et al. 2000) and so, the costs induced by oxidative stress may be a reliable currency in the trade-off between individual health and condition-dependent ornamental signal traits (Lozano 1994, 2001, Shykoff and Widmer 1996, von Schantz et al. 1999, but see Hill 1999). According to this hypothesis, individuals that are forced to fight infections during formation of carotenoid-based ornaments should allocate more carotenoids (and other antioxidants) into health maintenance and as a consequence less would remain for ornamentation. Hence, only the healthiest individuals would be able to express maximum coloration. Different aspects of this set of problems have recently been addressed in avian studies (reviewed by Møller et al. 2000). However, the proposed role of carotenoids and other antioxidants in mediating tradeoffs between individual health status and ornamental traits appears to be under continuous debate (e.g., Hill 1999, Lozano 2001) and undoubtedly awaits for further study.
The aim of this study is to describe relationships between fat-soluble antioxidants, plumage coloration and health status in brood-rearing great tits Parus major. The great tit is a small (ca. $19 \mathrm{~g}$ ) short-lived passerine, breeding in forests of most of the Eurasian Palearctic region (Gosler 1993). Males and females are phenotypically similar with the exception of the black breast stripe, which is larger in males than in females, and the yellow ventral coloration. The biochemical basis for the yellow plumage colour is lutein with some additional effects of zeaxanthin (Partali et al. 1987, Stradi 1998). Previous studies have demonstrated that great tits obtain lutein and zeaxanthin directly from their food and deposit those in their plumage during moult, apparently without any conversion of the biochemicals (Partali et al. 1987). The yellow ventral colour differs between sexes with males being more yellow than females (as measured using standard colour charts), between age classes with adults being more yellow than nestlings, and between habitats with great tits from deciduous habitats being more yellow than individuals from coniferous habitats (Slagsvold and Lifjeld 1985). A previous study in our great tit populations (using spectrophotometric measurements) revealed that great tits breeding in rural habitat had larger values of the hue of yellow plumage than their urban conspecifics, that males had larger hue than females, and that local survivors (to next breeding season) had larger hue than non-survivors. Additionally, the hue of the yellow plumage was related to prevalence of Haemoproteus blood parasites in an ageand sex-dependent manner (Hõrak et al. 2001). Thus, the great tit is a suitable organism for this kind of study because of its high prevalence of parasitism and use of carotenoids in plumage signals

To contribute to the understanding of possible mechanisms linking individual condition, health state and plumage coloration, we examine: (1) whether sex and habitat-linked differences in carotenoid-based plumage coloration reflect respective differences in individual plasma antioxidant concentrations, and (2) the covariation between plumage coloration and plasma antioxidant levels. We predict a positive correlation between plumage coloration and plasma carotenoid levels if individuals with more elaborate plumage coloration signal their ability to invest carotenoids in feathers, and relative carotenoid concentrations are consistent between individuals during the annual cycle (as found in at least one bird species; Saino et al. 1999). Alternatively, plasma carotenoid concentrations during breeding might primarily reflect variation in carotenoid content in diet. Finally, we will address the question of (3) whether plasma antioxidant levels relate to indices of immune system activation (hemoconcentration of different leukocytes and Haemoproteus infection). 


\section{Methods}

Data were collected in May 2000 in two neighbouring (urban and rural) great tit populations breeding in nest boxes in and around Tartu $\left(58^{\circ} 22^{\prime} \mathrm{N}, 26^{\circ} 43^{\prime} \mathrm{E}\right)$, SE Estonia (described by Hõrak and Lebreton 1998). The distance between the two study areas was $8 \mathrm{~km}$. In the period of first broods, adult great tits were captured at their nests when nestlings were 8 days old. Blood samples of $75-150 \mu 1$ were collected from the tarsal or brachial vein for determinations of antioxidants. To identify blood parasites and leukocytes, a drop of blood $(5-10 \mu \mathrm{l})$ was smeared on two individually marked microscope slides, air-dried, fixed in absolute methanol, and stained with azure-eosin. Slides were examined for blood parasites and leukocytes as described in Ots and Hõrak (1996) and Ots et al. (1998). Individuals were considered as infected when the smear contained at least one gametocyte of Haemoproteus per ca 10000 red blood cells.

To estimate non-parasitological indices of current immune function, we used leukocytic immune parameters, known to reflect the disease process, although not providing any specific diagnostic tests (see also Ots et al. 1998). In particular, we concentrated on the most numerous leukocyte types, namely heterophils, lymphocytes and eosinophils. The typical response to infectious diseases in birds is an increase in the total leukocyte count (WBC), mainly caused by an increase in the number of heterophils and/or lymphocytes (e.g., Dein 1986, Maxwell 1993). Eosinophils are prominent at sites of allergic reactions and with parasitic infections (helminths, nematodes, ectoparasites) and an elevated number of eosinophils usually indicates a response to abnormal cells, parasites or allergens (e.g., Wilson and Wilson 1978, Pastoret et al. 1998).

Analysis of plumage colour was performed on two pairs of two feathers, plucked from a standard position on the breast, the midpoint between the upper part of the sternum and the edge of the wing. The feathers were placed in a plastic bag and stored in darkness until measurements were made. Colour was measured in an approximately one $\mathrm{mm}^{2}$ area of the surface of the feather normally visible on the bird's body, using a portable spectroradiometer (Ocean Optics Europe, S2000) as described by Hõrak et al. (2001). To estimate colour, we used values of hue (as a correlate of the shape of the reflectance spectrum, measured in degrees around a circular spectrum) according to Endler (1990). Repeatability (Lessells and Boag 1987) of hue measurements (between averages of two pairs of feathers) was $0.72(\mathrm{n}=188$ individuals, $\mathrm{P}<0.0001)$.

Vitamin A, E and carotenoids were extracted from plasma with hexane after protein precipitation with ethanol as previously described by Surai et al. (2001). Vitamin E ( $\alpha$-tocopherol) and A (retinol) were determined as described by Surai et al. (1996) using an
HPLC system (Shimadzu Liquid Chromatograph, LC10AD, Japan Spectroscopic Co. Ltd. with JASCO Intelligent Spectrofluorometer 821-FP) fitted with a Spherisorb, type S30DS2, $3 \mu \mathrm{C}_{18}$ reverse phase HPLC column, $15 \mathrm{~cm} \times 4.6 \mathrm{~mm}$ (Phase Separations Ltd, UK). Chromatography was performed using a mobile phase of methanol/water $(97: 3, \mathrm{v} / \mathrm{v})$ at a flow rate of 1.05 $\mathrm{ml} / \mathrm{min}$ with a fluorescence detection of $\alpha$-tocopherol and retinol. Calibration was performed using $\alpha$-tocopherol and retinol solutions in methanol. Tocol was used as an internal standard.

Total carotenoids were determined from the same extract using the same HPLC system, but fitted with a Spherisorb, type S5NH2 $5 \mu \mathrm{C}_{18}$ reverse phase HPLC column, $25 \mathrm{~cm} \times 4.6 \mathrm{~mm}$ (Phase Separations Ltd., UK). Chromatography was performed using a mobile phase of methanol/water $(97: 3, \mathrm{v} / \mathrm{v})$ at a flow rate of 1.5 $\mathrm{ml} / \mathrm{min}$. Total carotenoids were detected at $445 \mathrm{~nm}$ as a single peak using lutein as a standard. A typical chromatogram of total carotenoid separation in this system is shown in Fig. 1. Individual carotenoids were determined by HPLC as described previously (Surai et al. 2001) using a Spherisorb type S3ODS2, 5- $\mu \mathrm{C}_{18}$, reverse-phase column, $25 \mathrm{~cm} \times 4.6 \mathrm{~mm}$ (Phase Separation, Clwyd, UK) with a mobile phase of acetonitrile-methanol (85:15) and acetonitriledichloromethane-methanol (70:20:10) in gradient elution using detection by absorbance at $445 \mathrm{~nm}$. Peaks were identified by comparison with the retention times of a range of carotenoid standards (variously obtained from Sigma, Poole, UK; Fluka, Gillingham, UK; Apin, Abingdon, UK; and Hoffman-La Roche, Basel,
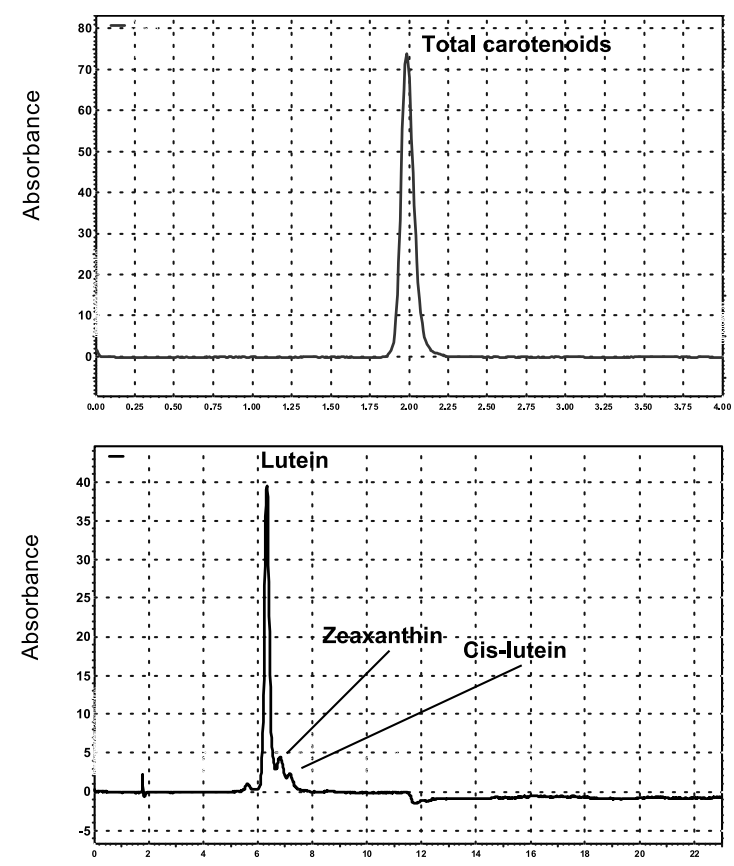

Fig. 1. HPLC of total and individual carotenoids in plasma. On $\mathrm{X}$-axis, retention time is given in minutes. 


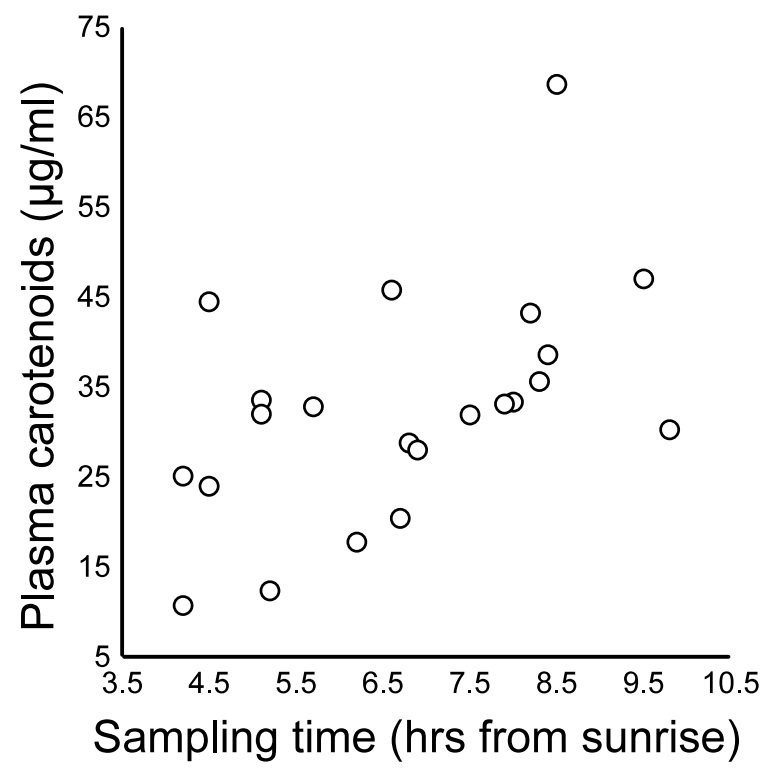

Fig. 2. Plasma carotenoids of brood-rearing great tits in relation to time of capture (from sunrise).

Table 1. Pearson correlations between plasma antioxidant concentrations. Data for carotenoids are partial correlations, adjusted for time of capture.

\begin{tabular}{lll}
\hline Variable & Carotenoids & Vitamin $\mathrm{A}$ \\
\hline Vitamin $\mathrm{E}$ & $\mathrm{r}=0.64, \mathrm{P}=0.002$, & $\mathrm{r}=0.71, \mathrm{P}=0.0005$ \\
Vitamin A & $\mathrm{n}=21$ & $\mathrm{r}=0.55, \mathrm{P}=0.014$, \\
& $\mathrm{n}=20$ & \\
\hline
\end{tabular}

Switzerland) as well as using coelution of individual carotenoids with known standards. Only lutein (73.2$84.5 \%)$, zeaxanthin $(9.6-15.8 \%)$ and cis-lutein $(3.4-$ $7.1 \%$ ) were detected in plasma (Fig. 1). Because of limited volumes of plasma samples for most of the individuals, we could not determine specific carotenoids, hence only results of total plasma carotenoids are analysed.

Values of all antioxidants were normally distributed with the exception of vitamin E. To normalise data, individual values of vitamin $\mathrm{E}$ were square root transformed before entered into ANCOVA models. To present data for comparisons, average vitamin E concentrations are showed untransformed. Because plasma carotenoid concentrations increased during the day, time of capture was included as a covariate in all models containing plasma carotenoid concentration as an independent variable. Fourteen birds out of 22 whose plasma antioxidants were measured comprised seven breeding pairs. This non-random sampling pattern did not affect our conclusions derived from the study because antioxidant levels of pair members did not correlate positively $(\mathrm{P}=0.3-0.5)$. Data are reported as mean $\pm \mathrm{SD}$, and all P-values are for twotailed tests.

\section{Results}

Plasma carotenoid concentration of great tits increased with the time of capture (Fig. 2). Concentrations of vitamin $\mathrm{A}$ and $\mathrm{E}$ did not vary with time $(\mathrm{r}=0.1-0.3$, $\mathrm{n}=20-21, \mathrm{P}=0.2-0.8$ ). Concentrations of all antioxidants correlated positively and significantly with each other (Table 1). We found no significant differences in plasma antioxidant concentrations of breeding great tits with respect to sex or study area $(\mathrm{F}=0-1, \mathrm{P}=0.3-1.0$; Table 2). Males had significantly larger values of hue of the yellow ventral feathers than did females $\left(\mathrm{F}_{1,18}=\right.$ $14.1, \mathrm{P}=0.002$ ) and rural birds had generally larger hue than urban birds $\left(\mathrm{F}_{1,18}=4.4, \mathrm{P}=0.053\right.$; Table 2$)$.

Plasma carotenoid concentration correlated positively with hemoconcentrations of lymphocytes and eosinophils (Table 3, Fig. 3). Birds with higher load of Haemoproteus gametocytes in their peripheral blood tended to have higher plasma concentrations of carotenoids and vitamin E (Table 3, Fig. 3). Relationships between parasites and antioxidants became significant in comparison of infected and uninfected individuals, and infected birds had higher concentrations of vitamin $\mathrm{E}$ (infected: $26.8 \pm 13.7 \mu \mathrm{g} / \mathrm{ml}$ vs. uninfected: $\quad 15.9 \pm 7.0 \mu \mathrm{g} / \mathrm{ml} ; \quad F_{1,20}=5.3, \quad P=0.033$, ANOVA) and carotenoids (infected: $39.8 \pm 10.4 \mu \mathrm{g} / \mathrm{ml}$ vs. uninfected: $29.2 \pm 10.4 \mu \mathrm{g} / \mathrm{ml} ; \mathrm{F}_{1,20}=4.9, \mathrm{P}=0.039$; least square means and SD, adjusted for time of capture in ANCOVA).

Table 2. Concentrations of fat-soluble antioxidants and plumage colour in male and female great tits, breeding in urban and rural study areas.

\begin{tabular}{|c|c|c|c|c|c|c|c|c|}
\hline \multirow[t]{3}{*}{ Variable } & \multicolumn{4}{|l|}{ Urban } & \multicolumn{4}{|l|}{ Rural } \\
\hline & \multicolumn{2}{|l|}{ Females } & \multicolumn{2}{|l|}{ Males } & \multicolumn{2}{|l|}{ Females } & \multicolumn{2}{|l|}{ Males } \\
\hline & Mean (SD) & $\mathrm{n}$ & Mean (SD) & $\mathrm{n}$ & Mean (SD) & $\mathrm{n}$ & Mean (SD) & $\mathrm{n}$ \\
\hline Carotenoids $(\mu \mathrm{g} / \mathrm{ml})$ & $33.7(18.0)$ & 8 & $32.4(11.3)$ & 7 & $26.2(8.1)$ & 2 & $33.6(7.1)$ & 5 \\
\hline Vitamin E $(\mu \mathrm{g} / \mathrm{ml})$ & $23.2(13.8)$ & 7 & $18.3(6.4)$ & 7 & $9.1(9.8)$ & 2 & $20.2(11.1)$ & 5 \\
\hline Vitamin A $(\mu \mathrm{g} / \mathrm{ml})$ & $0.73(0.26)$ & 7 & $0.74(0.08)$ & 6 & $0.47(0.60)$ & 2 & $0.94(0.42)$ & 5 \\
\hline Hue (degrees) & $57.2(3.2)$ & 7 & $62.6(2.3)$ & 6 & $61.2(2.0)$ & 2 & $64.7(2.9)$ & 4 \\
\hline
\end{tabular}


Table 3. Spearman rank correlations between plasma antioxidants, leukocyte hemoconcentrations and intensity of Haemoproteus blood parasites. Data for carotenoids are partial correlations, adjusted for time of capture.

\begin{tabular}{llll}
\hline Variable & Carotenoids $(\mathrm{n}=22)$ & Vitamin $\mathrm{E}(\mathrm{n}=21)$ & Vitamin A $(\mathrm{n}=20)$ \\
\hline WBC & $\mathrm{r}_{\mathrm{s}}=0.36, \mathrm{P}=0.1$ & $\mathrm{r}_{\mathrm{s}}=0.20, \mathrm{P}=0.4$ & $\mathrm{r}_{\mathrm{s}}=0.35, \mathrm{P}=0.1$ \\
Lymphocytes & $\mathrm{r}_{\mathrm{s}}=0.49, \mathrm{P}=0.025$ & $\mathrm{r}_{\mathrm{s}}=0.15, \mathrm{P}=0.5$ & $\mathrm{r}_{\mathrm{s}}=0.43, \mathrm{P}=0.057$ \\
Heterophils & $\mathrm{r}_{\mathrm{s}}=0.12, \mathrm{P}=0.6$ & $\mathrm{r}_{\mathrm{s}}=-0.02, \mathrm{P}=1$ & $\mathrm{r}_{\mathrm{s}}=-0.05, \mathrm{P}=0.8$ \\
Eosinophils & $\mathrm{r}_{\mathrm{s}}=0.52, \mathrm{P}=0.016$ & $\mathrm{r}_{\mathrm{s}}=0.24, \mathrm{P}=0.3$ & $\mathrm{r}_{\mathrm{s}}=0.30, \mathrm{P}=0.2$ \\
Haemoproteus & $\mathrm{r}_{\mathrm{s}}=0.43, \mathrm{P}=0.052$ & $\mathrm{r}_{\mathrm{s}}=0.42, \mathrm{P}=0.059$ & $\mathrm{r}_{\mathrm{s}}=0.23, \mathrm{P}=0.3$ \\
\hline
\end{tabular}

None of the plasma antioxidants was significantly associated with plumage hue $\left(\mathrm{F}_{1,13-15}=0.2-0.4, \mathrm{P}=\right.$ $0.5-0.7$ in ANCOVA models including sex and study area as factors and antioxidant concentration as a continuous predictor variable).

\section{Discussion}

Plasma carotenoid concentration of brood-rearing great tits increased during the day. The most parsimonious explanation for this pattern is that plasma carotenoid levels reflect the dietary input of carotenoid-rich food items and the respective accumulation of carotenoids in the plasma during the course of day. Low morning levels of carotenoids are likely to be caused by increased depletion of carotenoids during the night. For instance, blood leukocyte concentrations (Ots et al.
1998) and intestinal cell proliferation (Starck 1996) are known to increase during the night. High night-time cell proliferation activity in the gut has been associated with low antigen and high antioxidant (e.g., melatonin) concentration, which suppresses errors caused by free radicals during DNA replication (Starck 1996). Hence, diel rise of plasma carotenoids may result due to replenishing of nightly depleted antioxidant supplies.

Concentrations of all examined antioxidants revealed strong positive correlations with each other. There are two (not mutually exclusive) explanations for this pattern. First, positive correlations between concentrations of different antioxidants could result from the common dietary origin of carotenoids, and vitamin A and E. Second, this correlation may reflect complementary and synergistic action of antioxidants. If plasma antioxidant levels vary due to individual differences in total oxidative burden, then one might also expect a positive
Fig. 3. Relationships between plasma carotenoids and vitamin $\mathrm{E}$, and hemoparasite and leukocyte hemoconcentrations. Residual carotenoids are carotenoid concentration, adjusted for time of capture. Spearman rank correlation coefficients are presented in Table 3 .
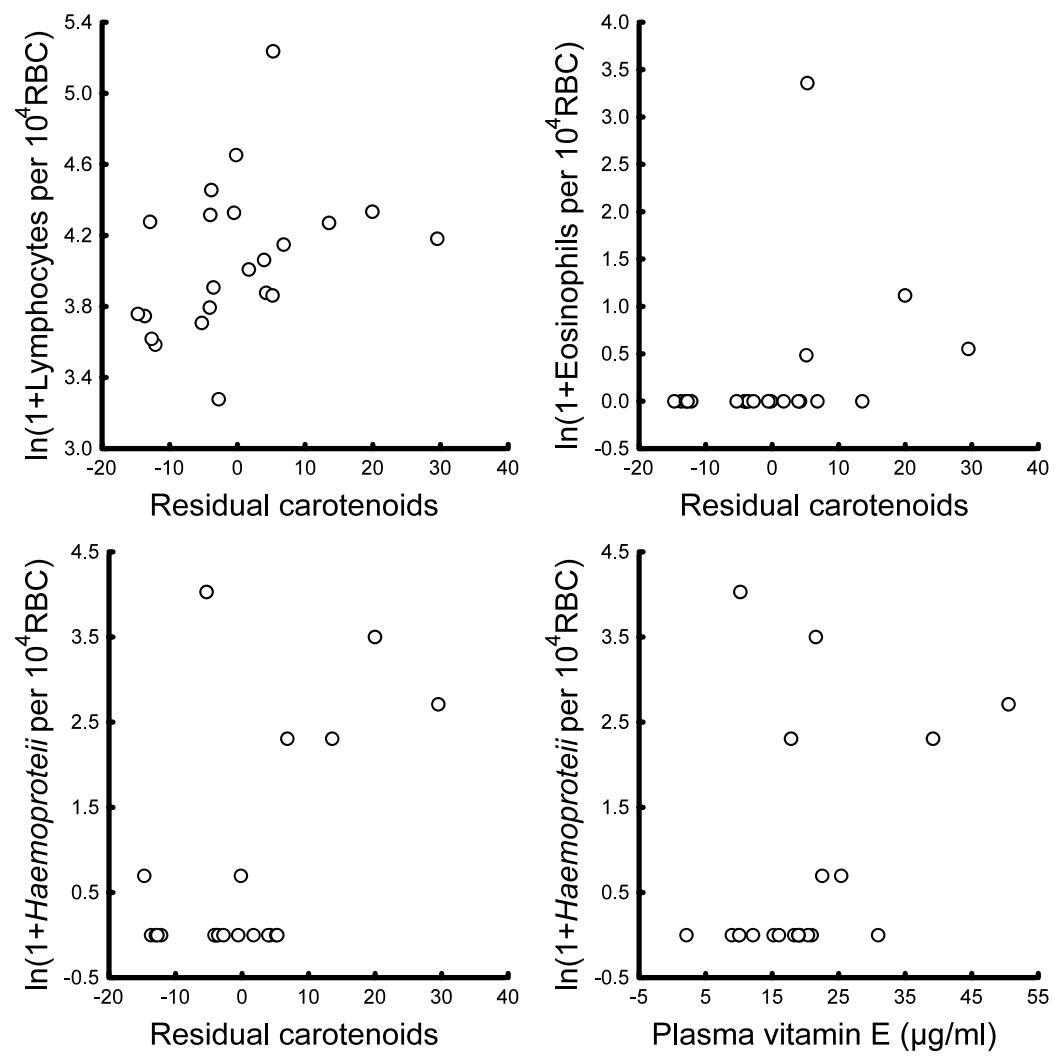
covariation between different antioxidants. This, in turn, would be consistent with carotenoids and vitamin $\mathrm{A}$ and $\mathrm{E}$ being limiting antioxidants. For a better understanding of these issues, it would be important to obtain data about accumulation of carotenoids in the liver. Carotenoid concentration in plasma is a reflection of a balance between dietary carotenoid consumption and their use. Plasma carotenoids can include carotenoids of portomicrones (dietary origin) and carotenoids of very low, low, and high density proteins (mainly released from the liver) (for review, see Surai et al. 2001a, Surai 2002). So, at present, we do not know whether increased plasma carotenoids primarily reflect increased release of carotenoids from the liver (for example to maintain immune competence), or whether it mainly indicates a lack of parasitic inhibition of the delivery of carotenoids from the intestinal tract to the liver. The same is true for vitamin E, since its absorption and assimilation in birds is similar to that for carotenoids (Surai 2002).

We failed to find any significant differences in plasma antioxidant concentrations between either female or male urban and rural great tits. Yet in the same sample of individuals, plumage colour differences between sexes and study habitats were significant (Table 2) and consistent with our previous findings (Hõrak et al. 2001). Due to low test power (6-8\%), we cannot conclude that plasma antioxidant levels did not differ between sexes and habitats with a small or intermediate effect size. Nevertheless, our results suggest that even if sex and habitat differences in plasma antioxidant levels were present, they were clearly less prominent than the respective differences in plumage colour. This result, as well as the lack of correlation between plumage colour and plasma antioxidants, can probably be explained by the superabundant availability of dietary carotenoids during the sampling period. Our great tits were captured in the middle of the nestling period, which is supposed to coincide with peak abundance of green caterpillars in nature (e.g., Nager and van Noordwijk 1995). Because caterpillars are an extremely rich source of carotenoids (Partali et al. 1987), it is likely that dietary carotenoids were not limiting for the great tits in this particular period of the year. Notably, remarkable seasonal differences in plasma carotenoid levels have been recorded in several other bird species (e.g., Hill 1995, Bortolotti et al. 1996, 2000, Negro et al. 1998, 2001).

Our result about lack of correlation between plumage colour and plasma carotenoids differs from that of Saino et al. (1999) who found that during the breeding season, coloration of read feathers on the throat of male barn swallows Hirundo rustica was positively correlated with plasma lutein concentration. To interpret the inconsistencies in results between these studies, it is important to note that plasma lutein concentration in the swallows was about ten times lower $(1-5 \mu \mathrm{g} / \mathrm{ml})$ than the total carotenoid concentration in our great tits $(5-70 \mu \mathrm{g} / \mathrm{ml}$, Fig. 2). Most likely, these differences can be ascribed to a lower content of carotenoids in aerial insects (the main food source of barn swallows) as compared to green caterpillars, which comprise the major food source for brood-rearing great tits. So, we might speculate that barn swallows are probably more carotenoid-limited than great tits while rearing their offspring. Hence, plasma carotenoid levels in swallows are probably more closely related to the general condition and health status of individuals. This reasoning would also explain why barn swallows revealed negative correlations between plasma carotenoid levels and eosinophile and heterophile hemoconcentrations (Saino et al. 1999), while in our great tits, a positive correlation between plasma carotenoids and lymphocyte and eosinophile hemoconcentrations emerged (Table 3; Fig. 3). Saino et al. (1999) interpreted their findings as being consistent with the prediction that turnover and metabolism of carotenoids is increased in infected individuals. Seriously infected individuals (as suggested by high concentrations of heterophils and eosinophils in the blood stream) should show lower carotenoid concentrations than healthy ones if carotenoids are depleted during free radical scavenging and participation in other immune modulating and immune stimulating processes.

Why then did a positive correlation emerge between antioxidants and immune cell concentrations, and between antioxidants and blood parasite infection? First, high plasma vitamin $\mathrm{E}$ and carotenoid levels of infected birds can possibly be associated with the immune modulatory properties of these antioxidants. For instance, it has been shown that dietary supplements of vitamin E can simultaneously enhance antibody responses and depress mitogen-induced proliferation of T-cells in domestic chicken (Leshchinsky and Klasing 2001). Additionally, $\alpha$-tocopherol can suppress release of a pro-inflammatory cytokine, IL$1 \beta$, from monocytes (Devaraj and Jialal 1999). At present we cannot exclude the possibility that such processes could potentially interfere with the abolishment of parasites from the organism.

Second, although carotenoids and other antioxidants can be seriously depleted during parasitic infections (e.g., Allen 1997), animals may sometimes rely on oxidative stress to fight infections. For instance, feeding rodents with diets supplemented with various fish oils (containing highly pro-oxidative polyunsaturated fatty acids) effectively reduced infections of Trypanosoma sp. and Plasmodium sp. These antiparasitic effects could be reversed by additions of vitamin E, indicating that effects of fish oil treatments were likely to be due to diet-induced oxidative stress (reviewed in Taylor et al. 1997, Allen and Danforth 1998, Allen et 
al. 1998). It is also known that avian coccidiosis can be effectively cured by feeding chickens leaves or major effector compounds of an annual wormwood Artemisia annua, a plant known to possess highly pro-oxidative activity due to endoperoxide functional group. This plant species has been used in China for over 2000 years to treat human malaria (Allen et al. 1997). In this context, we can speculate that higher carotenoid and vitamin E concentrations in great tits revealing gametocytes of Haemoproteus in their blood stream might relate to an inability of individuals to withstand infections effectively in situations of too high antioxidant levels. A similar mechanism might also explain the positive correlations between plasma carotenoids and hemoconcentrations of lymphocytes and eosinophils. Both leukocyte types are known to increase with various infections, including blood and intestinal parasites (e.g., Coles, 1997, Ots and Hõrak 1998), so we might again predict a positive correlation between the level of infection and plasma antioxidant levels. We suggest that conflicts between too high concentrations of plasma antioxidants and an organismal need to generate oxidative stress to fight parasites are especially likely to emerge in wild bird species whose plasma carotenoid contents are much higher than those of most mammals and poultry (e.g., Hill 1999). In this context, it is noteworthy that carotenoid concentrations found in the plasma of great tits in our study (average $32.6 \pm 12.7 \mu \mathrm{g} / \mathrm{ml}$, $\mathrm{n}=22$ ) exceed those found in other avian species ranging from $2.7 \pm 1.2 \mu \mathrm{g} / \mathrm{ml}(\mathrm{n}=41)$ in breeding barn swallows (Saino et al. 1999) to $22.5 \pm 9.33(\mathrm{n}=$ 87) in captive male American kestrels Falco sparverius during the mating period (Negro et al. 1998).

We can see two proximate reasons for the positive associations between indices of the immune system activation and plasma antioxidant levels. First, such an association can result mainly from an inability of individuals to reduce plasma carotenoid concentration (e.g., due to the necessity of maintaining high blood antioxidant levels for immune modulating or immune stimulatory purposes, or because for the time-limited great tit parents, carotenoid-rich caterpillars appear most abundant and nutritious food items, which can be collected at minimum foraging costs). Second, uninfected individuals may just need less antioxidants for the repair of molecules and immune cells which are normally damaged in inflammatory defence reactions. To distinguish between these alternatives, more information is needed about the currently unsolved question of the ability of individuals to control or regulate their antioxidant levels (see Negro et al. 1998). These aspects would be worth testing in future studies of species and populations with different baseline levels of antioxidants.
Acknowledgements - We thank Ene Sarapuu and Lea Tummeleht for field assistance and Helen Vellau for measuring plumage colour. Jan-Åke Nilsson and an anonymous referee provided constructive criticism on the ms. This study was supported by Estonian Science Foundation grant no 4537 to PH. P.F.S. was supported by the Scottish Executive Rural Affairs Department.

\section{References}

Andersson, M. 1994. Sexual selection. - Princeton Univ. Press.

Allen, P. C., Lydon, J. and Danforth, H. 1997. Effects of components of Artemisia annua on coccidia infections in chickens. - Poultry Science 76: 1156-1163.

Allen, P. C. 1997. Production of free radical species during Eimeria maxima infections in chickens. - Poultry Science 76: 814-821.

Allen, P. C. and Danforth, H. 1998. Effects of dietary supplementation with n-3 fatty acid ethyl esters on coccidiosis in chickens. - Poultry Science 77: 1631-1635.

Allen, P. C., Danforth, H. and Augustine, P. C. 1998. Dietary modulation of avian coccidiosis. - Int. J. Parasitol. 28: $1131-1140$

Bortolotti, G. R., Negro, J. J., Tella, J. L., Marchant, T. A. and Bird, D. M. 1996. Sexual dichromatism in birds independent of diet, parasites and androgens. - Proc. R. Soc Lond. B 263: 1171-1176.

Bortolotti, G. R., Tella, J. L., Forero, M. G., Dawson, R. D. and Negro, J. J. 2000. Genetics, local environment and health as factors influencing plasma carotenoids in wild American kestrels (Falco sparverius). - Proc. R. Soc. Lond. B 267: 1433-1438.

Cherian, G. and Sim, J. S. 1997. Egg yolk polyunsaturated fatty acids and vitamin E content alters the tocopherol status of hatched chicks. - Poultry Science 76: 1753-1759.

Coles, B. H. 1997. Avian medicine and surgery, 2nd ed. Blackwell Science, Oxford

Dein, J. 1986. Hematology. - In: Harrison, G. J. and Harrison, W. R. (eds). Clinical avian medicine. Saunders Co., London, pp. 174-191.

Devaraj, S. and Jialal, I. 1999. a-Tocopherol decreases interleukin $1 \beta$ release from activated human monocytes by inhibition of 5-Lipoxugenase. - Arterioscler. Thromb. Vasc. Biol. 19: 1125-1133.

Endler, J. A. 1990. On the measurement and classification of colour in studies of animal colour patterns. - Biol. J. Linnean Soc. 41: 315-352.

Gosler, A. 1993. The great tit. - Hamlyn, London.

Hamilton, W. D. and Zuk, M. 1982. Heritable true fitness and bright birds: a role of parasites. - Science 218: 384-387.

Hill, G. E. 1995. Seasonal variation in circulating carotenoid pigments in the house finch. - Auk 112: 1057-1061.

Hill, G. E. 1999. Is there an immunological cost to carotenoidbased ornamental coloration? - Am. Nat. 154: 589-595.

Hõrak, P. and Lebreton, J.-D. 1998. Survival of adult great tits in relation to sex and habitat: a comparison of urban and rural populations. - Ibis 140: 205-209.

Hõrak, P., Ots, I, Vellau, H., Spottiswoode, C. and Møller, A. P. 2001. Carotenoid-based plumage coloration reflects hemoparasite infection and local survival in breeding great tits. - Oecologia 123: 166-173.

Leshchinsky, T. V. and Klasing, K. C. 2001. Relationship between the level of dietary vitamin $\mathrm{E}$ and the immune response of broiler chickens. - Poultry Science 80: 15901599.

Lessells, C. M. and Boag, P. T. 1987. Unrepeatable repeatabilities: a common mistake. - Auk 104: 116-121.

Livrea, M. A., Tesorirre, L. and Friesleben, H. J. 1996. Vitamin $\mathrm{A}$ as an antioxidant. - In: Cadenas, E. and 
Packer, L. (eds). Handbook of antioxidants. Marce Dekker, New York, pp. 371-405.

Lozano, G. A. 1994. Carotenoids, parasites, and sexual selection. - Oikos 70: 309-311.

Lozano, G. A. 2001. Carotenoids, immunity, and sexual selection: comparing apples and oranges. - Am. Nat. 158: $200-203$.

Maxwell, M. H. 1993. Avian blood leucocyte responses to stress. - World's Poultry Science Journal 49: 34-43.

Møller, A. P., Biard, C., Blount, J. D., Houston, D. C., Ninni, P., Saino, N. and Surai, P. F. 2000. Carotenoid-dependent signals: Indicators of foraging efficiency, immunocompetence or detoxification ability? - Avian Poultry Biol. Rev 11: $137-159$.

Nager, R. G. and van Noordwijk, A. J. 1995. Proximate and ultimate aspects of phenotypic plasticity in timing of great tit breeding in a heterogeneous environment. - Am. Nat. 146: 454-474.

Negro, J. J., Bortolotti, G. R., Tella, J. L., Fernie, K. J. and Bird, D. M. 1998. Regulation of integumentary colour and plasma carotenoids in American kestrels consistent with sexual selection theory. - Funct. Ecol. 12: 307-312.

Negro, J. J., Tella, J. L., Hiraldo, F., Bortolotti, G. and Prieto, P. 2001. Sex- and age-related variation in plasma carotenoids despite constant diet in the red-legged partridge Alcetoris rufa. - Ardea 89: 275-280.

Olson, J. A. 1993. Vitamin A and carotenoids as antioxidants in physiological context. - J. Nutr. Sci. Vitamin. 39: S57-S65.

Ots, I. and Hõrak, P. 1996. Great tits Parus major trade health for reproduction. - Proc. R. Soc. Lond. B 263: 1443-1447.

Ots, I. and Hõrak, P. 1998. Health impact of blood parasites in breeding great tits. - Oecologia 116: 441-448.

Ots, I., Murumägi, A. and Hõrak, P. 1998. Hematological health state indices of reproducing great tits: methodology and sources of natural variation. - Funct. Ecol. 12: 700707.

Partali, V., Liaaen-Jensen, S., Slagsvold, T. and Lifjeld, J. T. 1987. Carotenoids in food chain studies: II. The food chain of Parus spp. monitored by carotenoid analysis. - Comp. Biochem. Physiol. B 87: 885-888.

Pastoret, P., Gabriel, G., Bazin, H. and Govaerts, A. 1998. Handbook of vertabrate immunology. - Academic Press, San Diego.

Puthpongsiriporn, U., Scheideler, S. E., Sell, J. L. and Beck, M. M. 2001. Effects of vitamin $E$ and $C$ supplementation on performance, in vitro lymphocyte proliferation, and antioxidant status of laying hens during heat stress. Poultry Science 80: 1190-1200.

Ross, D. A. 1998. Vitamin A and public health: Challenges for the next decade. - Proc. Nutr. Soc. 57: 159-165.
Saino, N., Stradi, R. Ninni, P., Pini, E. and Møller, A. P. 1999. Carotenoid plasma concentration, immune profile and plumage ornamentation of male barn swallows (Hirundo rustica). - Am. Nat. 154: 441-448.

Shykoff, J. A. and Widmer, A. 1996. Parasites and carotenoid based signal intensity: how general should the relationship be? - Naturwissenschaften 83: 113-121.

Slagsvold, T. and Lifjeld, J. T. 1985. Variation in plumage color of the great tit Parus major in relation to habitat season and food. - J. Zool. 206: 321-328.

Starck, J. M. 1996. Phenotypic plasticity, cellular dynamics, and epithelial turnover of the intestine of Japanese quail (Coturnix coturnix japonica). - J. Zool. 238: 53-79.

Stradi, R. 1998. The colour of flight. - Solei, Milan.

Surai, P. F. 1999. Vitamin E in avian reproduction. - Poultry Avian Biol. Rev. 10: 1-60.

Surai, P. F. 2002. Natural antioxidants in avian nutrition and reproduction. - Nottingham Univ. Press, Nottingham, UK

Surai, P. F., Noble, R. C. and Speake, B. K. 1996. Tissue-specific differences in antioxidant distribution and susceptibility to lipid peroxidation during development of the chick embryo. - Biochimica et Biochysica Acta 1304: 1-10.

Surai, P. F., Speake, B. K. and Sparks, N. H. C. 2001a. Carotenoids in avian nutrition and embryonic development. 1. Absorption, availability and levels in plasma and egg yolk. - J. Poultry Science 38: 1-27.

Surai, P. F., Speake, B. K. and Sparks, N. H. C. 2001b. Carotenoids in avian nutrition and embryonic development. 2. Antioxidant properties and discrimination in embryonic tissues. - J. Poultry Science 38: 117-145.

Surai, P. F., Speake, B. K., Wood, N. A. R., Blount, J. D., Bortolotti, G. R. and Sparks, N. H. C. 2001. Carotenoid discrimination by the avian embryo: a lesson from wild birds. - Comp. Biochem. Physiol. B 128: 743-750.

Taylor, D. W., Levander, O. A., Krishna, V. R, Evans, C. B. Morris, V. C. and Barta, J. R. 1997. Vitamin E-deficient diets enriched with fish oil suppress lethal Plasmodium yoelii infections in athymic and scid/bg mice. - Infection and Immunity 65: 197-202.

von Schantz, T., Bensch, S., Grahn, M., Hasselquist, D. and Wittzell, H. 1999. Good genes, oxidative stress and condition-dependent sexual signals. - Proc. R. Soc. Lond. B 266: $1-12$.

Wilson, G. R. and Wilson, L. P. 1978. Haematology, weight and condition of captive red grouse (Lagopus lagopus scoticus) infected with caecal threadworm (Trichostrongylus tenuis). - Research in Veterinary Science 25: 331-336.

(Received 16 December 2002, revised 12 March 2003, accepted 17 April 2003.) 